\title{
Los saberes y los oficios en el contexto de la economía transnacional
}

\author{
Amalia Miano ${ }^{1}$
}

\author{
Categoría: Artículo \\ Fecha de recepción: 28 de mayo de 2012 \\ Fecha de aprobación: 25 de julio de 2012
}

\begin{abstract}
Resumen
En este artículo se analizan las transformaciones que se dan en cuanto a los saberes para usar tecnología por trabajadores que ejercen oficios tradicionales tales como costura, herrería, cocina y carpintería. Este análisis forma parte de una investigación más amplia desarrollada en una localidad rural de seis mil habitantes del sur de la provincia de Santa $\mathrm{Fe}$, Argentina. Se trata de un pueblo en el cual se han instalado en la última década empresas transnacionales del sector de la agroindustria de la alimentación. Los resultados muestran que en este contexto se instituyen determinados saberes como los adecuados para acompañar las transformaciones que se dan en el mercado de trabajo local mientras que otros saberes ligados a la práctica, al aprendizaje en interacción, al conocimiento sobre el funcionamiento interno de máquinas y herramientas se convierten en saberes obsoletos.
\end{abstract}

Palabras clave: saberes - oficios - economía transnacional.

\begin{abstract}
This paper analyses the transformations in knowledge needed to use technology by workers who perform traditional trades such as needlework, blacksmithing, cooking and carpentry. This analyses is framed in a wider research developed in a small town in Santa Fe, Argentine, where deeps changes have been taking place for one decade. Amongst the most relevant transformations is the process associated with the settlement of transnational companies. Results show that certain knowledge are instituted as appropriate to accompany the transformation in local labor market while other knowledge, related to practice and learning in interaction, become obsolete.
\end{abstract}

Key- words: knowledge - traditional trades - transnational economy.

1 Doctora en Ciencias Sociales, Facultad de Ciencias Sociales Universidad de Buenos Aires. Instituto Rosario de Investigación en Ciencias de la Educación (IRICECONICET) e Instituto para la Inclusión Social y el Desarrollo Humano (INCLUIR). mariamaly@hotmail.com. 


\section{Introducción}

En El taller y el cronómetro (1979), Benjamín Coriat analiza la forma en que el taylorismo, como tecnología particular de control del trabajo asalariado, descompone el saber de los trabajadores de oficios en un "conjunto de gestos de producción concebidos y preparados por la dirección de la empresa" (Coriat, 1982: 36). Ese saber, que era visto por el obrero como un patrimonio familiar transmisible únicamente a los hijos, se había erigido como un recurso de poder para los obreros hábiles en el contexto de la revolución industrial, en tanto permitía un control de los modos de operar y de los tiempos en los procesos industriales de trabajo.

De la misma manera en que a comienzos del siglo XX la introducción de tecnologías de organización del trabajo implicó una modificación en los saberes de los trabajadores de oficios, a comienzos del siglo XXI se vuelve necesario volver a analizar el estado de esos saberes en el contexto de la economía transnacional $^{2}$. Esto permitirá dar cuenta de la forma en que, a pesar de la introducción progresiva de tecnología automatizada en los espacios de trabajo, de la deslocalización y fragmentación de los procesos de trabajo y de técnicas que apuntan a erosionar la heterogeneidad de los saberes (por mencionar sólo algunas de las características que adquiere el trabajo humano en la actualidad), muchos trabajadores de oficios siguen aprendiendo, enseñando y reproduciendo su vida material y la de su familia alrededor del ejercicio de un oficio que ha sido transmitido, en la mayoría de los casos, de generación en generación.

Este artículo apunta a analizar las maneras y los ámbitos a través de los cuales se aprenden y transmiten saberes para ejercer oficios tradicionales, prestando particular atención a los saberes

2 Entendida como un proceso que implica "la creciente transnacionalización de los procesos económicos y sus correlatos políticos y socioculturales que caracterizan a una nueva etapa de desarrollo del capitalismo mundial y que producen marcadas transformaciones en las sociedades locales" (Villafañe, 1998: 85). 
requeridos para usar tecnología ${ }^{3}$ en estos ámbitos de trabajo. Para esto, se analizarán entrevistas realizadas a cinco trabajadores (una costurera, una cocinera, un carpintero y dos herreros) que viven en una pequeña localidad del sur de la provincia de Santa Fe, Argentina. Se trata de un pueblo cuya actividad económica principal fue la explotación agropecuaria hasta mediados de la década del 2000, momento en que se instalan dos empresas transnacionales ligadas al sector de la agroindustria de la alimentación ${ }^{4}$ y una empresa generadora de energía eléctrica ${ }^{5}$. A partir de esto, comienzan a gestarse algunos cambios desde el Gobierno Comunal en relación con la capacitación de la mano de obra local y se instituyen algunos saberes específicos como los adecuados respecto a las transformaciones acaecidas en el mercado de trabajo local. Por ejemplo, en el año 2007, el Gobierno Comunal abrió una escuela de oficios con el objetivo de capacitar mano de obra que luego pueda llegar a insertarse en las empresas. En este espacio se dictan talleres de carpintería, electricidad doméstica, soldadura y gasista. También, se han abierto talleres en los que se enseña inglés, computación, perito clasificador de granos y una tecnicatura en agroindustrias de la alimentación. En varias ocasiones distintos miembros del Gobierno Comunal han manifestado la idea de que ciertos saberes ligados al trabajo manual y el uso de herramientas no eléctricas se

3 En esta investigación, la categoría analítica de tecnología abarca el conjunto de herramientas, máquinas y formas de organizar el trabajo dirigido a satisfacer las necesidades humanas. Se partió de suponer que en el ámbito de los trabajadores de oficios, la definición de tecnología y lo que se identificaría como tal estaría asociada a herramientas manuales y modos de hacer transmitidos a través de generaciones. En tanto el trabajador es en muchos casos hacedor de la propia tecnología, tiene el control en el manejo de las herramientas, mientras que el espacio de trabajo se constituye como un lugar en el cual habría posibilidades de crear y proyectar con la ayuda de los implementos tecnológicos. (Miano, 2012).

4 Se trata de las empresas Noble Group, cuya actividad en la planta instalada en la localidad es la recepción, almacenamiento y embarque de granos para exportación, y Dreyfus, cuya planta desarrolla las mismas actividades que la anterior pero le agrega una planta de molienda de granos para la producción de aceite y harina de soja.

5 Se trata de la Termoeléctrica San Martín, un fideicomiso constituido por el Estado Argentino (52\%) y el resto por distintas empresas privadas transnacionales. 
convierten en saberes obsoletos, apostando a un tipo de formación de la mano de obra local acorde a las necesidades de mano de obra calificada que manifiestan los gerentes de las plantas. Es decir, si bien en la escuela abierta por el Gobierno Comunal se enseñan oficios tradicionales, se instala discursivamente la idea de que la formación brindada en ese espacio apunta a "la industria" o a "los procesos de tecnificación" acordes a los requerimientos de las empresas transnacionales.

Las preguntas que nos proponemos responder en este artículo son: ¿cuáles son los saberes que los trabajadores de oficio ponen en juego al generar y usar tecnología en sus actividades productivas? ¿De quiénes y dónde aprendieron esos saberes? ¿Cómo se transmiten saberes sobre la tecnología en las actividades productivas? ¿Qué tipo de destrezas hacen posible? ¿Cómo se actualizan esos saberes al transformarse los contextos en los que son aplicados? ¿Hay marginación o adaptación de saberes en el contexto de la economía transnacional? La hipótesis de trabajo que subyace a estas preguntas es que, en procesos de cambios ligados a la economía transnacional como los que se están experimentando en la localidad en la que se desarrolló el trabajo de campo, hay determinados saberes que resultan marginados, generando, por un lado, que la mayor parte de los trabajadores de oficios de la localidad tengan que cerrar sus talleres y, por otro, que la mayor parte de la población quede excluida de los puestos de trabajo en las empresas recientemente instaladas.

\section{Metodología de investigación}

La investigación de la cual se comentarán en este artículo cuestiones relacionadas específicamente a los saberes y los oficios en el contexto de economía transnacional, forma parte de una tesis doctoral ${ }^{6}$ finalizada que se desarrolló en el marco de dos

6 Para optar por el título de Doctor en Ciencias Sociales, Facultad de Ciencias Sociales, 
instituciones de ciencia y técnica de Argentina ${ }^{7}$. El objetivo general de esta investigación fue observar, describir e interpretar una serie de prácticas cotidianas desarrolladas por trabajadores de oficios, trabajadores de las plantas instaladas en la localidad, docentes y estudiantes de dos ámbitos educativos de la localidad y miembros del Gobierno Comunal, a los fines de comprender el impacto de las transformaciones socio-económicas, políticas y culturales a partir de la instalación de tres empresas en la costa de la localidad mencionada.

El trabajo de campo comenzó en el mes de septiembre de 2008 y se extendió hasta el mes de septiembre de 2009. La investigación se encuadró en un enfoque teórico-metodológico transdisciplinar que combinó aportes de la etnografía, los Estudios Sociales de la Tecnología, la historia de la educación y los estudios sobre desarrollo local y rural. Se realizaron 20 entrevistas a actores de distintos ámbitos de la localidad (el Gobierno Comunal, la escuela media, la cooperativa agraria, las empresas transnacionales, comerciantes locales, trabajadores de oficios), con el fin de obtener información precisa sobre algunos temas de especial interés para la investigación. En algunos de estos ámbitos también se han realizado observaciones escritas y video grabadas.

En este artículo se trabajará específicamente con ocho entrevistas realizadas a los trabajadores de oficios de la localidad. Algunas de estas entrevistas han sido video grabadas siguiendo la premisa de que las imágenes generan un tipo de conocimiento etnográfico diferente al que permiten otros tipos de registros (por ejemplo, escritos u orales). En este sentido, el video permitió hacer recorridos en los talleres en los cuales los trabajadores de oficios ejercen sus actividades cotidianas. En estas situaciones, las

Universidad de Buenos Aires. La tesis fue titulada "A este pueblo le vino la modernización de golpe. Reconfiguración de saberes y sentidos en torno a la tecnología en una Comuna del sur de la provincia de Santa Fe", y defendida en el mes de marzo de 2012. 7 Estas Instituciones son el Instituto para la Inclusión Social y el Desarrollo Humano (INCLUIR) y el Instituto Rosario de Investigación en Ciencias de la Educación (IRICE). 
entrevistas implicaban instancias de observación de las prácticas cotidianas de estos trabajadores y de las máquinas y herramientas presentes en estos espacios. El hecho de que el registro audiovisual permita involucrar los cuerpos físicos de las personas, sus voces, sus movimientos y los entornos, abre la posibilidad de comprender las realidades etnográficas de una forma sensorial, directa e inmediata (Torresan, 2011). Siguiendo este enfoque, una de las características distintivas del trabajo de investigación desarrollado por el equipo de INCLUIR es el trabajo con imágenes (fijas y móviles) como documentos (Gastaminza, 2002) que, al yuxtaponerlos con información generada en otros formatos (escrito, oral), permiten una reconstrucción densa y variada de la complejidad que acontece durante el trabajo de campo (Heras, 2009a; Heras, Bergesio y Burin, 2004). En este artículo se incluirán algunas imágenes que han sido extraídas de las entrevistas audio grabadas para analizar el vínculo entre los oficios, las tecnologías y los saberes.

\section{La innovación tecnológica y los saberes de los trabajadores}

Desde las formulaciones realizadas por Karl Marx (1980; 1987) acerca de la introducción de maquinaria automática en los espacios de trabajo, varios autores de la sociología del trabajo han formulado la pregunta acerca de si la incorporación de nuevas tecnologías (tales como la microelectrónica, los sistemas automáticos, la robótica, las máquinas-herramientas de control numérico computarizado) en los espacios de trabajo requiere que los trabajadores pongan en juego saberes más complejos e integrados o, por el contrario, conlleva a la descalificación de los trabajadores. Se pueden mencionar dos autores que ejemplifican estas dos posturas. César Aira formula la figura de "los bricoleurs domésticos" para dar cuenta de aquellas personas que tienen la habilidad de desarmar distintas máquinas (autos, radios, lavarropas, relojes) hasta la última pieza y volverlas a armar. Esta acción permite te- 
ner un saber extremadamente útil acerca de cómo funcionan las máquinas. Para el autor, desde mediados del siglo XX, principalmente como consecuencia de la introducción de la electrónica en la construcción de las máquinas, este saber ya no tiene razón de ser y ha perdido vigencia:

[] la humanidad dejó de saber cómo funcionan las máquinas que usa. Lo saben, en forma parcial y fragmentaria, algunos ingenieros en los laboratorios de Investigación y Desarrollo de algunas grandes empresas, pero el ciudadano común, por hábil y entendido que sea, les perdió la pista hace mucho. Hoy día todos usamos los artefactos como usaban antaño las damas el automóvil: como cajas negras con un Input (apretar un botón) y un Output (se enciende el motor), en la más completa ignorancia de lo que sucede entre esos dos extremos (Aira, 2001: 4).

Ese saber acerca del funcionamiento de los artefactos que se ha perdido y se ha trasladado al uso, implicaba poner en acción un tipo de inteligencia particular que se adentraba a develar ciertos mecanismos, cierta cadena de causas y efectos, conformando así un saber que permitía predecir lo que podría llegar a pasar. El placer obtenido de esta clarividencia compensaba la ardua tarea de desarmar y volver a armar, cuyo resultado era siempre volver al mismo artefacto desde el que se había partido.

La tesis de Aira parece ser que con el paso de la tecnología electromécanica a la electrónica, muchas prácticas referentes a la manipulación de los artefactos se ven clausuradas y por lo tanto, se da una pérdida de los saberes necesarios para esa manipulación (saberes que para el autor son complejos y delimitan un tipo de inteligencia particular). Como tesis contraria, se puede mencionar el trabajo de Raffaele Simone, La tercera fase. Formas de saber que estamos perdiendo (2001), en el cual para la autora, en la "sociedad del conocimiento" (identificada como contrapuesta a la "sociedad tradicional" ubicada temporalmente como ante- 
rior a la expansión de la informática) los saberes se han acrecentado cuantitativamente: "la masa de conocimientos necesarios para vivir (es decir, para actuar, trabajar, hacer funcionar las manufacturas de todo tipo, moverse, etc.) se ha incrementado enormemente" (Simone, 2001: 68) y cualitativamente:

[] los conocimientos que utilizamos, incluso en muchos ámbitos de la vida cotidiana, son inmensamente más complejos que antes: hacen necesarias sofisticadas cadenas de pasos ("haz antes esto, después lo otro, después esto otro todavía"), se hacen referencia entre sí, están jerarquizados según árboles complejos, etcétera (Simone, 2001: 82).

A diferencia de Aira, para la autora la electrónica y la informática han generado una sofisticación de los saberes necesarios y circulantes en la sociedad para manipular los artefactos de la vida cotidiana y la tecnología presente en los espacios de trabajo.

Siguiendo a Martín Spinosa (2005), se pueden sintetizar cuatro posturas respecto al vínculo entre las habilidades o saberes de los trabajadores y la innovación tecnológica: 1) la de "los autores provenientes de la tradición marxista clásica, herederos de Harry Braverman" (Spinosa, 2005: 152), que sostienen que las nuevas tecnologías generan una disminución del contenido cognitivo del trabajo y que las tareas se vuelven más sencillas y rutinarias; 2) la de "los gurúes de la sociedad del conocimiento" que postulan que en tanto la tecnología se ha vuelto más compleja, requiere de los trabajadores un mayor nivel de calificación; 3) la idea de la "polarización de las calificaciones", es decir, se crean nuevos empleos que requieren de una alta carga cognitiva, mientras que, por otro lado, la mayor parte de los puestos de trabajo requieren de tareas rutinarias y monótonas; 4) algunos estudios cuantitativos que sostienen que "existen puestos que exigen más nivel de calificación y de complejidad en los saberes absolutos; pero si se pudiese distinguir un quantum de saber existente en la sociedad, éste estaría disminuyendo" (Spinosa, 2005: 153). 
Luego de presentar este breve diálogo en torno a la tecnología y los saberes, a continuación se desarrollarán algunas dimensiones centrales del concepto de reservorios de conocimientos ("funds of knowledge") (Moll, 1992; Vélez-Ibáñez y Greenberg, 1992) que resultarán útiles para indagar lo que sucede con los saberes en contextos de transformaciones ligadas al mercado de trabajo.

Con el fin de comprender las maneras en que las familias de inmigrantes mexicanos que habitan en el sur de los Estados Unidos intentan controlar y adaptar sus recursos culturales para enfrentar el proceso de industrialización y los cambios del mercado de trabajo, Carlos Vélez-Ibáñez y James Greenberg (1992) postulan el concepto de funds of knowledge ("reservorios de conocimiento"). El mismo da cuenta de un "cuerpo de conocimientos de importancia estratégica" (Vélez-Ibáñez y Greenberg, 1992: 314, traducción propia) que se pone en juego en las diversas actividades que se realizan en la vida cotidiana, por ejemplo, la comprensión de las características del ecosistema local, habilidades para la construcción, control de plagas, manejo de animales, mantenimiento y reparación de equipos y herramientas, conocimientos sobre hierbas medicinales, entre otros.

Los contenidos de estos reservorios son dinámicos, es decir, se adaptan y cambian de acuerdo a las transformaciones que se dan en la "realidad empírica" (Vélez Ibáñez y Greenberg, 1992: 318). Para mantener enriquecidos y actualizados esos reservorios, las redes sociales a las que recurren los trabajadores para resolver sus problemas diarios cumplen un papel fundamental. De esta manera, los reservorios se manifiestan en los intercambios que se dan entre amigos o conocidos con el fin de obtener información para conseguir un trabajo o consejos para asistir a agencias del Estado. Este tipo de ayuda basada en el obtener y dar información resulta más significativa que la ayuda financiera. En tanto los trabajadores dependen de estas redes sociales para lidiar con las transformaciones económicas que se dan en el mercado de 
trabajo, hay una gran inversión de energía y recursos para mantener las buenas relaciones con los miembros de estas redes. Para los autores, a través de la inserción e interacción que se da hacia el interior de estas redes, los reservorios son constantemente renovados y actualizados.

Una dimensión relevante del concepto de reservorios es el de la interacción social. El carácter interactivo de la cognición es abordado por los autores al analizar específicamente la forma en que los niños mexicanos inmigrantes en Estados Unidos incorporan conocimientos en el marco de sus actividades domésticas. En el desarrollo de estas actividades, los niños tienen la oportunidad de "experimentar" los conocimientos con la compañía de un adulto. En este proceso los chicos pueden hacer preguntas a los adultos y pueden ir poniendo en juego "el comportamiento aprendido" (Vélez-Ibáñez y Greenberg, 1992: 326, traducción propia). En este proceso cognitivo se sigue una lógica de ensayo y error que le aporta al niño cierta comodidad ya que los errores no son penados.

Un último aspecto a destacar del concepto de reservorios de conocimientos tiene que ver con las estrategias formales e informales que desarrollan las familias para aprender nuevas habilidades. Según Moll (1992), las estrategias formales dependen de instituciones (escuelas, centros de formación, talleres de oficios, entre otros) y requieren de mucho tiempo y algunas veces, de recursos financieros que las familias no tienen al alcance de su mano. Si bien estas instituciones proveen credenciales educativas, no garantizan un empleo y a menudo no proveen los conocimientos ni la experiencia necesaria para conseguir un empleo. Por el contrario, las estrategias informales (de las cuales, por ejemplo, el trabajo temporario, o lo que se conoce como "changas" son las más frecuentes) se presentan como oportunidades de adquirir nuevas habilidades, ya que muchas veces en estas situaciones se da el encuentro con otras personas que poseen otros reservorios y los ponen en juego en esa actividad a desarrollar. 
Estas estrategias informales permiten la experimentación y proveen experiencia a quienes participan de ellas.

\section{Los saberes y el oficio en el contexto de la economía transnacional}

Luego de haber desarrollado las principales dimensiones analíticas que se pueden desprender del concepto de reservorios de conocimientos y de haber recorrido algunas posturas teóricas en torno al vínculo entre tecnología y saberes en los espacios de trabajo, en este apartado se expondrá el análisis de las entrevistas realizadas a los cinco trabajadores de oficios de la localidad (una cocinera, una costurera, un carpintero y dos herreros). Se entiende por "trabajadores de oficios" a aquellos que portan un saber específico ligado a los procesos de fabricación (Coriat, 1982) realizados con el fin de transformar el mundo material circundante en el marco de actividades productivas. Estos trabajadores parten de materias primas ya dispuestas para su transformación, y para realizar este proceso se sirven de instrumentos, máquinas y herramientas elaboradas por otros o por ellos mismos. La mayoría de los entrevistados complementa el ejercicio del oficio con otras actividades (la docencia, el trabajo de la tierra en baja escala, la producción y venta de artesanías, entre otras actividades).

\section{Las experiencias laborales y el ámbito doméstico como espacios de aprendizaje de saberes}

Al recorrer su trayectoria laboral, los trabajadores de oficios mencionan a las actividades realizadas en el marco de determinadas experiencias de trabajo (ser operario en una fábrica, trabajar en un taller de carpintería o herrería, ser profesor en la escuela primaria, cocinar comida para vender en fechas festivas, trabajar ocasionalmente como peón rural en la época de cosecha, reparar máquinas por encargo) como instancias en las cuales han aprendido saberes que ponen en juego al realizar sus actividades 
productivas. De esta manera, los ámbitos de trabajo se instituyen como espacios en los que se dan oportunidades de aprendizaje (Heras 1995; Heras 2009b; SBCDG, 1995) de saberes ligados a los oficios:

[] en toda situación interactiva se producen, en forma dinámica, situaciones que permiten a quienes interactúan, generar conocimientos de índoles diversas (...); en cada contexto y situación, quienes interactúan traen su historia y sus deseos a futuro, que operan en forma concreta y específica, al momento de producir conocimiento. (Heras, 2009b: 97).

En tanto las diversas experiencias de trabajo por las que transita el trabajador son identificadas por ellos mismos como instancias en las cuales se da la oportunidad de aprender nuevos saberes y habilidades, se puede sostener la idea de la flexibilidad y dinamismo de los saberes en tanto éstos se actualizan y enriquecen en el transcurso de la experiencia laboral del trabajador. A su vez, estos saberes son dúctiles y maleables en tanto pueden ser trasladados entre ámbitos diversos; por ejemplo, Juan, el carpintero, reconoce que el aprendizaje que tuvo que realizar para dictar la materia de tecnología en el marco de su trabajo como profesor de la escuela primaria luego le sirvió para instalar la huerta en el predio de la casa quinta de la cual es casero; Ivo, que actualmente está jubilado pero combinó durante la mayor parte de su vida el oficio de herrería con el trabajo rural, menciona su trabajo como operario en la fábrica de máquinas como un ámbito en el que realmente "aprendió a usar el torno", saber que luego le permitió abrir junto a sus hermanos un taller de carpintería y herrería.

El ámbito doméstico es identificado por los trabajadores como otro espacio en el que se dan oportunidades de aprendizaje, al mirar y ejecutar actividades en el marco familiar cuya finalidad es el autoconsumo o la generación de ingresos. En los tres casos en que se identificó al ámbito doméstico como uno de los espacios en los que se han aprendido saberes que resultaron 
significativos para el desarrollo de las actividades productivas, se trató de dos mujeres (Marcela, la costurera y Angélica, la cocinera) y de una persona cuya infancia transcurrió entre los años 1920 y 1930 (Ivo). Esto puede estar dando cuenta, por un lado, de la transmisión de los saberes para la realización de las actividades domésticas cotidianas entre las mujeres de la familia y, por otro, de la forma en que se organizaba el trabajo familiar a principios de siglo XX en las colonias agrícolas, con la participación cotidiana de los menores en las actividades productivas.

[] a la mañana según, a la salida del sol más o menos, a veces antes, porque a veces veníamos a la escuela a la tarde y no a la mañana, pero si no a la mañana íbamos a arar, cuatro caballos, un arado de dos rejas, dos cuerpos que le dicen, yo iba de a pie y mi hermana manejaba el caballo, cuando llegábamos a la punta, yo levantaba una palanca para levantarle el arado y ella manejaba el caballo, y ella habrá tenido 9 años y yo 7,8 años, por ahí, muy diferente de ahora, si ahora hasta que tienen 17 años no hay que trabajar, yo me acuerdo que a los 5 años ya trabajaba, dentro de la casa se hacía todo, íbamos a cortar yuyos en el maíz, el maíz nos tapaba a nosotros, no era que levantabas la cabeza y veías afuera, no, el maíz era más alto que uno. (Ivo, herrero, 21 de mayo de 2009).

[] uno viene de una familia grande donde mi mamá siempre cocinó para casas de familia, doméstica siempre, y por lo general, cocinera, y en mi caso, por ejemplo, llegaba navidad y había que hacer 20 matambres, cocinar 3 lechones, no para mi casa sino para entregar, o sea que... si bien mi mamá no era de las que decían "vení, aprendé", pero de tanto ver, terminás aprendiendo. (Marcela, cocinera, 6 de noviembre de 2008).

[] lo conozco al trabajo [de costurera] porque lo vi, desde que nací y no porque fui a aprender ni nada. (Juliana, hija de Angélica, 4 de septiembre de 2009). 
En estos testimonios, el saber se plasma en actividades que han sido mencionadas por los trabajadores en sus relatos: "íbamos a arar", "yo iba de a pie y mi hermana manejaba el caballo", "yo levantaba una palanca", "trabajar", "se hacía todo", "cocinó", "de tanto ver terminás aprendiendo", "conozco el trabajo porque lo vi". Estas actividades y otras que han sido mencionadas por los trabajadores, son identificadas a la vez como oportunidades de aprendizaje y como manifestaciones del saber, aunque en ninguno de los casos aparezca de forma explícita en el relato de los trabajadores la palabra "saber". De esta manera, el aprendizaje realizado por Marcela al ayudar a su mamá a cocinar comida para vender le permitió contar con saberes que luego pudo aplicar en su trabajo como cocinera del comedor escolar. Juliana manifiesta "conocer" el trabajo de costurera por haber crecido en un hogar en el cual su mamá realizaba permanentemente ese trabajo. Ese conocimiento le permite actualmente participar del taller de costura abierto por el Gobierno Comunal y poder recibir un ingreso por su participación en ese taller. Ivo aprendió desde pequeño saberes ligados a las actividades productivas rurales que le permitieron luego continuar con esta actividad y complementarla con la herrería. A través de estos testimonios que dan cuenta de una forma de transmisión de los saberes a través de la ejecución de actividades, de la convivencia y el trabajo cotidiano en el ámbito doméstico, se puede sostener que el contexto familiar se convierte en un ámbito de análisis fundamental al analizar la constitución de los saberes, en tanto

[] a través de la familia, el niño constituye su relación con el saber en lo más íntimo de su psiquis, pero también en el contexto del grupo familiar y de la cultura familiar con su inscripción social, por la cual el individuo aprende de una manera a relacionarse con los diferentes saberes presentes en la sociedad. (Beillerot, Laville y Mosconi, 1998: 15).

La escolarización y la posterior formación pueden modificar la relación con el saber que se constituyó inicialmente en el marco 
familiar, por lo tanto, para estos autores es necesario analizar los saberes desde un ángulo institucional y socio-histórico.

Además de constituirse como un ámbito en el que se dan oportunidades de aprendizaje, el contexto familiar facilita muchas veces el acceso a experiencias de trabajo convirtiéndose en la puerta de entrada al mundo laboral, acercando la posibilidad de encarar un emprendimiento productivo familiar en el que participan varios miembros del entorno familiar (hermanos, sobrinos e hijos), o bien permitiendo realizar trabajos ocasionales:

La secundaria la hice trabajando a la par de mi mamá, mi mamá siempre agarraba algún trabajo... los agarraba ella porque por ahí a mí de chiquita no me daban bolilla, pero agarraba un trabajo más y me lo pasaba a mí, después llegaban las vacaciones o los cambios de temporada y me agarraba ella, 5 o 6 patronas de ella para hacer por ejemplo el cambio de guardarropas, levantar todos los acolchados, troquelar todo... y después ya me llamaban para eso, ese era el trabajo de las vacaciones de invierno y de verano (Marcela, 16 de noviembre de 2008).

[] trabajé en un lugar en el que se fabricaban toda clase de tornos, toda clase de máquinas, herramientas, fabricaban la máquina de hacer hilo, unas máquinas como de 15, 20 metros de largo, eran todos carreteles para la lana, ahí sí aprendí, ahí aprendí lo que era el torno, porque aparte de lo que hacía uno, uno veía a los otros que trabajaban, en dos turnos se trabajaba y ahí aprendí. Después cuando volví acá, con mi hermano compramos un torno y hacíamos el mismo trabajo que en la fábrica, porque ya más o menos sabía, yo hacía las piezas... todo acá, los cuatro hermanos acá. Teníamos herrería, carpintería, hacíamos carrocerías para acoplados, hicimos acoplados nuevos, todo, después dos hermanos fallecieron (Ivo, 21 de mayo de 2009). 
En la actualidad, las oportunidades de aprender saberes y habilidades en el contexto de las actividades productivas realizadas en el marco familiar parecen estar desapareciendo. Esta tendencia tiene que ver con el hecho de que muchos talleres que funcionaban a la vez como espacios de trabajo y como lugares en los que se aprendía junto a familiares al ejecutar las actividades productivas, han cerrado porque dejaron de ser rentables. Por otro lado, se experimentan fuertes cambios en las formas de organizar el trabajo en el marco familiar, relacionados con la separación entre el lugar de residencia y el lugar de trabajo (Albanesi y Propersi, 2006) y la disminución de la participación de los hijos menores en las actividades productivas familiares. En este mismo sentido, al hacer su análisis sobre la adaptación de los funds of knowledge conforme a las transformaciones acaecidas en el mercado de trabajo ligadas a la industrialización, la mecanización de los procesos de trabajo y la introducción de nuevas tecnologías en la producción, Vélez-Ibáñez y Greenberg postulan que "la creciente separación entre las funciones del conocimiento en el lugar de trabajo y el hogar" (1992: 317, traducción propia) genera una pérdida de control sobre los conocimientos necesarios para la reproducción familiar y para desarrollar actividades productivas que generen algún tipo de ingreso económico.

\section{La interacción como constitutiva del aprendizaje}

Los ámbitos domésticos y laborales se convierten en lugares propicios para experimentar y aprender saberes bajo la guía de un compañero de trabajo con mayor experiencia o "que sabe más". Al reflexionar acerca de la forma en que han aprendido los saberes para usar tecnología en el marco de sus actividades productivas, los trabajadores siempre mencionan que han aprendido con otra persona. Esto lleva a afirmar la importancia de la interacción social en los procesos de cognición (Moll, 1992)

[] aprendí a manejar un tractor, aprendí a manejar arado, disco [] la reja, todo, todas esas herramientas que se 
usaban antes las aprendí a manejar con un tractor, que me enseñó un muchacho que sabía, que trabajaba en una quinta, y bueno, él me enseñó todo eso, compramos un tractor, compramos las herramientas y todo eso y bueno, me di el gusto de hacer mi propia quinta para poder vender a gran escala, cultivo intensivo, digamos. (Juan, 13 de noviembre de 2008).

La máquina industrial la aprendí a usar con otra chica que había antes que sabía usar la máquina, la compramos, averiguamos cómo funciona esto, cómo funciona lo otro y después les enseñamos a las chicas. (Angélica, 15 de noviembre de 2008).

Yo soy soldador, no digo que soy el mejor pero, en una palabra, sé bastante, y lo aprendí todo de la experiencia de los más grandes que me fueron pasando... me fueron pasando siempre el aprendizaje. (Daniel, 26 de junio de 2009).

A través de estos testimonios se puede dar cuenta de la importancia que adquiere contar con el acompañamiento de una persona de mayor experiencia que guía el proceso de aprendizaje. El saber de esta persona adquiere la forma de un saber sabido en términos de Beillerot (1998: 21) "lo que ha sido adquirido, un estado estático y una apropiación íntima, algo que, se supone, no ha de ser olvidado ni perdido. En el saber hay certidumbre y carácter definitivo". Esta persona se reconoce o bien porque es el propietario de un saber específico ("pienso que si vos tenés un maestro de carpintería va a salir un carpintero, si tenés un maestro en soldadura van a salir soldadores", Daniel, 26 de junio de 2009) que muchas veces se cuantifica en términos relativos (es el que "sabe más"), o bien porque tiene más años ("los que enseñaban eran los más viejos", Daniel) lo cual llevaría a legitimar su saber adquirido a través de la experiencia de trabajo. Al transmitir su saber, esta persona habilita en el otro una serie de acciones y formas de proceder que no hubiesen estado presentes sin su in- 
tervención. Por lo tanto, este proceso de aprendizaje genera en el sujeto que aprende una transformación ya que le permite contar con nuevos recursos para poder actuar sobre el mundo. Tal como lo postula el concepto de oportunidades de aprendizaje (Heras, 2009b), la interacción se constituye como una de las condiciones que permiten la construcción del saber.

Para dar cuenta de las mejores condiciones en las cuales desarrollar el proceso de enseñanza y aprendizaje de saberes, Juan hace referencia a la figura del aprendiz. En esta figura se sintetizan algunos elementos fundamentales para el proceso de aprendizaje; por un lado, la presencia insoslayable de un maestro que posee el saber y ejecuta el trabajo bajo la mirada atenta del aprendiz; por otro, la posibilidad de aprender a través de la experimentación, del hacer de la misma manera en que lo hace el maestro que sabe más; por último, subyace la concepción clásica de educación de Émile Durkheim (1976) basada en la acción ejercida por una generación de adultos sobre una generación de jóvenes:

[] ser un aprendiz es muy importante, porque no solamente aprendés las técnicas y el mantenimiento de las herramientas, sino todo lo que tiene adentro una herramienta [] vos de chico aprendés todo, todo, por eso pienso que ser aprendiz es la mejor base de una persona (Juan, 13 de noviembre de 2008).

En sus instancias de aprendizaje, los trabajadores mencionan que la transmisión del saber se da de manera modulada y hay una progresión en la dificultad de la ejecución de las tareas que se le asignan al aprendiz y un aumento de responsabilidades a medida que pasa el tiempo y se adquiere más experiencia

[] yo como pibe más chico posiblemente me daban alguna pintada, lijar hierros para digamos, para pintarlos ellos o por ahí pintaba a mano algunas cosas, o sea, trabajo liviano que a la vez me iban enseñando, viste. Después con el tiempo ya uno empezó a querer hacer el trabajo de los más grandes, bueno, entonces empecé a soldar, había 
gente que te enseñaba a soldar, alguien te enseñaba tornería, otro te enseñaba carpintería, ahí adentro mismo te enseñaban carpintería (Daniel, 26 de junio de 2009).

En este proceso de aprendizaje los trabajadores mencionan de manera frecuente tres acciones: ver ("lo conozco al trabajo por haberlo visto desde que nací", "de tanto ver terminás aprendiendo", "se hicieron maestros aprendiendo y viendo cómo se hacía la cosa, nada más"), hacer y también reflexionar sobre lo hecho. Como se destacó más arriba, el saber se manifiesta en la acción y es adquirido a través de la práctica. No hay posibilidad de aprendizaje si no hay una práctica que permita poner en juego el saber y una vez que ese saber es aprendido determina y da forma a la práctica. Puede interpretarse que la referencia que los trabajadores hacen a la acción de ver en los procesos de aprendizaje se deriva del propio carácter del saber como práctica:

[] en muchas situaciones de aprendizaje informal de oficios, lo que se "transmite" no es un "saber", sino un "trabajo" o una "experiencia" (...) Cuando los saberes y los saberes-hacer no son objetivados sino, al contrario, indisociables de los hombres (de los cuerpos) que los ponen en acción, el aprendizaje se hace únicamente por mimetismo (ver-hacer/hacer como) y en relación interpersonal (Lahire, 2006: 140-141, comillas en el original).

De esta manera, el saber que se manifiesta en la acción se exterioriza bajo la forma de actividades, maneras de proceder, secuencias, sensaciones (olores, colores, densidades) y hábitos corporales que son captados, fundamentalmente, a través de la mirada. El hecho de que la vista sea identificada por los propios trabajadores como el sentido más importante que se pone en juego en los procesos de aprendizaje, apuntala la idea de que el saber se manifiesta a través de prácticas y que se transmite a través de métodos culturalmente constituidos como, por ejemplo, la experimentación bajo la guía de un adulto o un compañero que sabe más (Moll, 1992). 


\section{Aprendizaje formal y constitución de saberes}

$\mathrm{Al}$ referirse a los ámbitos y situaciones en los cuales reconocen haber aprendido saberes que ponen en juego en sus actividades productivas, en muy pocos casos los trabajadores hacen referencia a su tránsito por el sistema educativo formal u otros ámbitos identificados explícitamente como espacios en los que se enseñan saberes (talleres, cursos de capacitación y otros). Tanto Ivo como Juan poseen títulos otorgados por el sistema educativo que se encuentran en relación directa con el ejercicio de su oficio. Ivo estudió durante 5 años (entre los años 1933 y 1938) en la Escuela San José de Rosario para obtener el título de Maestro mecánico, y Juan realizó sus estudios del Magisterio para obtener el título de Maestro especializado en trabajos manuales que lo habilitó a ejercer como profesor de la escuela primaria. Si bien en sus relatos hacen referencia al tránsito por estas instancias de formación, no las identifican como situaciones en las que han aprendido saberes sino más bien como requisitos a cumplir para poder ingresar en el mundo laboral; incluso, Ivo menciona que "mi diploma era un diploma provincial, pero nunca lo usé para nada, lo guardé allá y ahí quedó". Sólo Daniel menciona dos situaciones en las cuales aprendió saberes en el marco de ámbitos creados explícitamente para aprender que luego le sirvieron para desarrollar sus actividades productivas: la escuela primaria y secundaria y un curso realizado en el INTA (Instituto Nacional de Tecnología Agropecuaria):

[] para una herrería, aprender las mediciones, circunferencias, cómo sacar un radio, eso, vale mucho, viste, eso lo poco que se aprendió fue en la escuela primaria y secundaria, después fue todo muy liviano.

[] hice curso de capacitación en el INTA, el INTA antes daba muchos cursos de capacitación, daban... ¿cómo te podría decir? Te daban la oportunidad de que vayas a consultarlos y ellos te orientaban, viste, hice cursos integrados de plagas, o sea, saber qué bicho es bueno para el 
cereal, qué bicho es malo, son todos cursos de capacitación a nivel, digamos, campo, viste (Daniel, 26 de junio de 2009).

En síntesis, los trabajadores de oficios identifican y mencionan mayormente a determinadas experiencias de trabajo o actividades realizadas en el ámbito doméstico como instancias en las que se aprendieron saberes que luego pudieron ponerse en juego para desarrollar actividades productivas, mientras que los espacios y tiempos "oficiales" de transmisión de saberes no se reconocen como ámbitos privilegiados de aprendizaje. Tal vez, esto se debe al carácter eminentemente práctico de los saberes puestos en juego para el ejercicio de los oficios (tal como se desarrolló más arriba) que se contrapone con la forma de enseñanza tal como se da en los espacios educativos formales apoyados principalmente en la teoría. Es decir, si el aprendizaje de saberes ligados a los oficios se realiza siempre a través de la interacción y la puesta en práctica de esos saberes, un tipo de enseñanza que se centre en el dictado teórico de conocimientos no resultará relevante para estos trabajadores. De hecho, para los trabajadores de oficios realmente se genera un aprendizaje cuando a éste se lo lleva a la práctica, mientras que la teoría no es identificada como una oportunidad de aprendizaje:

[] lo que contiene la escuela primaria, ya en séptimo grado ya se perdió, no tiene más práctica el chico, tienen todo teoría, va a primer año, ya en primer año no hace más nada y ahí ya el chico ya no tiene orientación, le cuesta mucho orientarse al chico después, termina el secundario y "¿qué hago?”, “¿me voy a una escuela técnica?", “¿sigo el profesorado?”

[] hoy yo di un examen de electricidad y yo dije "si podemos hacer la práctica la hacemos y si no la tenemos que dejar", me querían hacer primero la práctica, no el examen teórico, a ellos no les importaba el examen teórico, y lo hicieron bien el examen, dentro de lo que yo les 
pude transmitir, lo aprendieron, sí, lo asimilaron, casi el $90 \%$ se va a sacar bien, pero ellos querían hacer la práctica, no querían hacer la teoría, no les importa la teoría, es como que vienen medio preparados. (Juan, 13 de noviembre de 2008).

[] hay que llevarlo a la práctica, uno sigue el estudio pero hay que llevarlo a la práctica (Daniel, 26 de junio de 2009).

Ahora bien, esta preferencia por la práctica como método privilegiado para la transmisión de saberes útiles para el ejercicio de oficios no implica que se tenga una aversión por los libros y revistas. De hecho, estos trabajadores mencionan en varias situaciones que para aprender a usar algunas máquinas han "leído" manuales de instrucciones o bien que muchas veces han consultado revistas o libros para obtener de ellos modelos, diseños y procedimientos. En la siguiente imagen (Figura 1) Juan muestra una heladera que tiene en su taller de carpintería en la que guarda libros que consulta frecuentemente y comenta:

[] esa heladera como la vés está llena de libros, así como la ves, está llena de libros, pero por falta de lugar... bueno, ¿ves? Está llena de libros, de lo que vos quieras hablar y hacer [], desde armar una cabaña hasta hacer artesanías. (Juan, taller de carpintería, 13 de noviembre de 2008).

Figura 1: Juan en su taller de carpintería. Imagen extraída de una entrevista video grabada. 13 de noviembre de 2008.

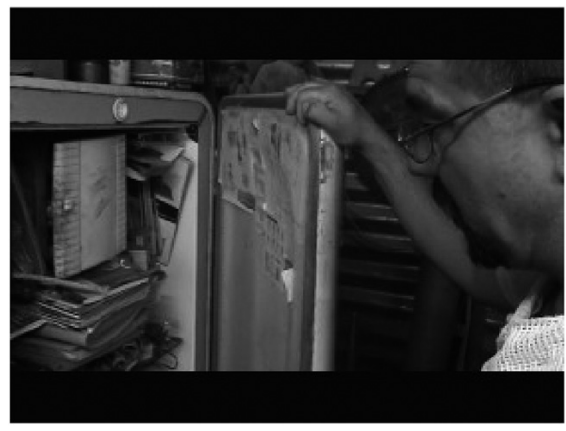


Para Sarlo (2004), el saber técnico venía a cumplir la proeza de una nivelación social ya que para adquirir este saber sólo bastaba con el hacer y consultar libros, diarios y revistas de divulgación (por ejemplo, las revistas Hobby o Mecánica popular, que han sido mencionadas por algunos de los trabajadores). El saber técnico, en tanto se convierte en un saber accesible para todos, es más democrático que el saber académico y no sólo eso, sino que también posibilita formas originales de adquisición del saber.

La técnica (o lo que se entienda por técnica), las nociones científicas divulgadas por manuales y las notas periodísticas ocupan el lugar de la ciencia impartida en la universidad y de los saberes de la élite letrada, no reemplazándolos sino otorgándole a la cultura que los incorpora la respetabilidad y el prestigio que tienen las organizaciones más tradicionales del conocimiento (Sarlo, 2004: 13).

La práctica de adquisición de saberes técnicos a través de la consulta de libros, identificados estos últimos como dispositivos de saber tradicionales, le aporta a los saberes ligados al hacer la legitimidad propia de los saberes letrados, ligados a la teoría y la contemplación. El trabajador de oficios se presenta a sí mismo como un hombre cuya pertinencia es el hacer, que no se hace prescindiendo de los libros y la lectura, aunque esta lectura se restrinja al manual de instrucciones que acompaña a un artefacto.

Otra forma de adquirir saberes, siguiendo las formulaciones de Vélez Ibáñez y Greenberg (1992), es a través de los intercambios que se dan hacia el interior de las redes sociales a las que asisten las personas para resolver sus problemas cotidianos. En estos intercambios, los reservorios se materializan y actualizan a través de la información que se obtiene o se brinda entre amigos o conocidos de manera cotidiana y constante.

[] cuando estás hablando a lo mejor te preguntan algo, las medidas de los bulones o cuál es el bulón que es de acero y entonces vos les decís: "bueno, el que está marca- 
do en tal lado", eso sí... pero, a lo mejor un consejo, hay gente acá que me ha venido a preguntar alguna cosa, viste, cómo desarmar, cómo hacer (Daniel, 26 de junio de 2009).

Como puede verse en este testimonio, a través de recurrir a conocidos que se identifican como aquellos que pueden portar y transmitir algunos saberes específicos, se generan instancias de adquisición de saberes que permiten resolver problemas en el marco de las actividades productivas.

\section{El conocimiento interno de las máquinas y herramientas}

La posibilidad de lograr una nivelación social a través de la adquisición de saberes técnicos (Sarlo, 2004) no residía únicamente en la facilidad en el acceso a esos saberes, que, como se desarrolló más arriba, puede darse a través del hacer, de la consulta de libros y revistas de divulgación y de intercambios hacia el interior de las redes sociales que los propios trabajadores van tejiendo en el transcurso de su trayectoria laboral. El carácter democrático del saber técnico residía también en que la factura material de los artefactos tecnológicos los hacía maleables (desarmables y armables). De esta manera, el acceso y la dominación de éstos se realizaba a través de un saber que se dirigía a conocer el mecanismo interno de los artefactos, en palabras de Aira (2001), el funcionamiento de los mismos.

Para lograr el aprendizaje de este tipo de saber se requirió de un sistema educativo formal que implementó dispositivos de enseñanza que estaban dirigidos a conformar este tipo de saberes. Es decir, se contó con un sistema educativo formal funcional a un modelo productivo que requería de trabajadores con habilidades orientadas al funcionamiento de los artefactos, capaces de construir, armar y desarmar mecanismos. De esta manera, la escuela se convirtió en transmisora de saberes orientados por un proyec- 
to nacional de industrialización. La enseñanza de las distintas partes que conforman una máquina era un aspecto fundamental en el aprendizaje de oficios. Esto puede verse en las siguientes imágenes (Figuras 2 y 3) que se corresponden con un registro audiovisual en el que Ivo muestra su cuaderno del año 1934 de la escuela de mecánica de Rosario.

Figuras 2 y 3: Cuaderno de la Escuela de Mecánica de Ivo Bressán. Imágenes extraídas de una entrevista video grabada. 25 de junio de 2009.


Estas imágenes proveen información acerca de la forma de enseñanza de los oficios en la década de 1930. En su paso por la escuela de mecánica, como parte de su aprendizaje, una de las tareas que tenían que realizar los alumnos consistía en dibujar las distintas partes de los artefactos (en las imágenes se observan un motor de motocicleta y un reductor de velocidad) y ubicarlas como en un rompecabezas "para saber cómo está hecho el motor" (Ivo, 25 de junio de 2009). Otro dispositivo de enseñanza consistía en realizar visitas a distintas fábricas para conocer sobre los distintos procesos de producción (Ivo mencionó, por ejemplo, la fábrica de autos Ford).

Para los trabajadores de oficios conocer realmente una máquina o herramienta implica conocer su interior, lo cual los capacita para desarmar estos artefactos hasta la última pieza y volverlos a armar: "los motores, ahora no porque dejé, pero los motores antes los armaba y los desarmaba... y no funcionaban más (risas), no...un chiste" (Ivo, 21 de mayo de 2009). Además de los 
ámbitos formales de aprendizaje de oficios, la práctica realizada en los propios lugares de trabajo permitía acceder a este tipo de conocimiento interno de máquinas y herramientas.

[] yo a los 12 años ya aprendí a manejar todas las máquinas, porque ahí [en el taller de carpintería] me las hacían desarmar, limpiarlas, el mantenimiento me lo hacían hacer, permanentemente, todos los fines de semana había que dejarlas engrasadas, limpias para el lunes, el taller tenía que quedar todo limpio y preparado para empezar a trabajar el lunes, y los fines de semana era mantenimiento, limpieza y orden (Juan, 13 de noviembre de 2008).

[] te enseñaban a usar las herramientas, ¿me entendés? Entonces después podés hacer cualquier otro tipo de trabajo sabiendo primero usar las herramientas y cómo, para qué sirve cada una, en vez hoy en día vos mandás a un muchacho joven y no sabe ni para qué sirven las herramientas. (Daniel, 26 de junio de 2009).

Los trabajadores comparten la sensación de que el saber interno acerca de las máquinas y herramientas y la funcionalidad de las mismas se ha ido perdiendo con el paso del tiempo. Las revistas de divulgación que los trabajadores mencionaron como de consulta frecuente también apuntaban a aportar saberes procedimentales que capaciten a las personas para construir, armar y desarmar artefactos. Sin embargo:

Hacia la década de 1950, antes del gran salto, cuando todavía se estaban desarmando autos y heladeras en el patio, circulaba una profusa bibliografía con patéticos intentos de seguirle el rastro al progreso. En las páginas de Mecánica Popular o la recordada Hobby se quemaban los últimos cartuchos con artículos sobre el funcionamiento de la propulsión a chorro o el televisor; pero los suscriptores se rendían, desalentados (Aira, 2001: 4). 
Probablemente, como afirma Aira, con la introducción de la tecnología electrónica se ha creado una caja negra que clausura la posibilidad de acceso a los mecanismos internos y, como consecuencia, a aquellos saberes que permitían develar estos mecanismos. Con la clausura al acceso directo a la materia y al develamiento de mecanismos de causas y efectos, cae también la posibilidad de nivelación social a través del acceso a saberes técnicos, ya que lo que se clausura es la propia posibilidad de acceso a un saber que convertía al saber técnico en un saber diferencial y calificado.

\section{Conclusiones}

$\mathrm{Si}$, por un lado, la introducción de maquinaria automática en los procesos de producción implicó, tal como lo describió Marx (1980), una erosión de los saberes especializados de los trabajadores y una reducción del trabajo creativo a la sucesión de tareas simples y repetitivas, $\mathrm{y}$, por otro, la introducción del taylorismo provocó la descomposición del saber del obrero de oficio en acciones predeterminadas, la introducción de la electrónica convierte a la especificidad del saber técnico en un saber sin sentido. El hecho de que los artefactos tecnológicos se hayan convertido en cajas negras, puede estar dando cuenta de una lucha contra uno de los últimos bastiones: un tipo específico de saber técnico, que permitía al hombre dominar y conocer los artefactos que lo rodean.

En el contexto de transformaciones experimentadas en la localidad relacionadas con la economía transnacional, determinados saberes en torno al uso de tecnología automatizada se instituyen como los adecuados, mientras que los saberes hacer que permiten integrar elementos heterogéneos (materialidad, conocimiento social, saberes acerca del funcionamiento interno y los mecanismos de los artefactos, posibilidad de desviar la función original de las cosas, entre otros), se convierten en saberes desactualizados. En este proceso se genera una valoración diferencial de los saberes 
cuyo resultado es una jerarquización social. La contracara de esta jerarquización es la marginación de determinados saberes que se consideran como obsoletos y que por lo tanto no son funcionales al modelo económico histórico y particular (Foucault, 2008) que se encuentra en configuración en el ámbito local. Esto repercute en el ámbito de los trabajadores de oficios que comparten la sensación de que su oficio ligado a las actividades manuales es algo que se está perdiendo en la actualidad. En algunos casos, la pérdida del oficio que se experimenta en la actualidad constituye el punto final de una larga historia de transmisión de saberes y espacios de trabajo entre distintas generaciones de una misma familia. Esta pérdida del oficio manual, artesanal, es experimentada como algo irremediable por los trabajadores.

Las transformaciones experimentadas en las formas de organizar las actividades en el marco familiar; la desaparición de ámbitos laborales que funcionaban al mismo tiempo como espacios en los que se transmitían saberes a través del hacer; la transformación material de la tecnología cuya constitución clausura la posibilidad de poner en juego el saber sobre el funcionamiento interno de un artefacto, saber que convertía al técnico en un especialista indispensable para la generación y uso de tecnología; la capacitación de mano de obra orientada al manejo de tecnología eléctrica y automatizada para acompañar las transformaciones ligadas a la economía transnacional, se constituyen como factores que ponen en juego la supervivencia y transmisión de los saberes de los oficios ligados a las actividades manuales.

En las plantas de las empresas transnacionales instaladas en la Comuna, los saberes sobre los procesos manuales de fabricación y sobre los mecanismos internos de los artefactos son suplantados por un saber sobre sistemas informáticos de operación; es decir, ya no es necesario saber cómo funcionan los artefactos porque la intervención del hombre sólo es necesaria en caso de que falle algún sector de ese sistema y el saber que se tiene del funcionamiento del mismo no es total sino parcializado y seg- 
mentado en función de las distintas partes que conforman el artefacto. Esto lleva a que de los cien trabajadores que emplean cada una de las plantas muy pocos sean de la localidad ya que, según los gerentes, había en el pueblo muy poca gente capacitada para ingresar a trabajar allí. Los que lo hacen ocupan puestos de vigilancia, limpieza y peritos clasificadores de granos.

En síntesis, en el contexto de la economía transnacional, en la localidad se observa un desplazamiento de los saberes desde las actividades rurales y el ejercicio de oficios tradicionales hacia la adquisición de saberes específicos ligados a los requerimientos de las empresas recientemente instaladas. Como se mencionó más arriba, estos saberes son promovidos por el Gobierno Comunal a través de la apertura de talleres de oficios en los cuales se le da a la enseñanza una orientación basada en las transformaciones acaecidas en el mercado de trabajo local. Ejemplos de esto son la tecnicatura en agroindustrias de la alimentación que se dicta en la escuela secundaria de la localidad en el tuno noche desde el año 2007, el curso de perito recibidor de granos y la apertura de los talleres de computación e inglés por parte del Gobierno Comunal. Es necesario aclarar que estos dos últimos talleres son los que tienen mayor asistencia de los 24 talleres del área de cultura abiertos por el Gobierno Comunal, lo cual es un indicio más de la importancia que adquiere para los pobladores locales el aprendizaje de determinados saberes específicos ligados a las transformaciones productivas que se están experimentando en la localidad, ligados en este caso a la informática y el aprendizaje de idiomas, en tanto se trata de empresas transnacionales dedicadas principalmente a la logística de materias primas hacia países extranjeros.

Además de este desplazamiento de saberes desde y hacia ámbitos diferentes de aplicación, se percibe una mayor institucionalización en el aprendizaje de saberes, es decir, las actividades domésticas y la propia experiencia laboral parecen no ser suficientes como instancias de aprendizaje de saberes que luego per- 
mitan ingresar a trabajar en las empresas de la zona, sino que lo que se vuelve imprescindible es la realización de cursos dictados por instituciones oficiales y la obtención de una titulación otorgada por el sistema educativo formal. Si bien, como afirma Moll (1992), estas estrategias formales para aprender habilidades y saberes no garantizan un empleo ni proveen la experiencia necesaria para resolver las actividades productivas, proporcionan credenciales educativas que se convierten en requisitos para acceder a determinados puestos de trabajo.

A pesar de este panorama, el recorrido realizado en este artículo sobre las formas y los ámbitos en los cuales se generan aprendizajes ligados a la tecnología en el marco de oficios tradicionales, lleva a pensar que los trabajadores, a través de una organización social y económica singular, siguen poniendo en juego, adquiriendo y actualizando sus saberes. Éstos han sido transmitidos de generación en generación, a través de prácticas culturalmente situadas, en cada nueva oportunidad de trabajo que surge a través de las redes sociales que van construyendo en su trayectoria laboral. Estos saberes, además de ser flexibles y adaptables a los cambios suscitados en el contexto, son transversales, en tanto pueden ser aplicados a diferentes dominios de la producción y se conforman como verdaderas maneras de hacer (De Certeau, 1996) que abren la posibilidad de resistir al proceso de homogeneización de las actividades laborales planteado por el capitalismo contemporáneo.

\section{Bibliografía}

Aira, César (2001): "La utilidad del arte". Ramona. Revista de artes visuales. $N^{\circ} 15,4-5$. Albanesi, Roxana y Propersi, Patricia (2006): "Familias rurales y estructura agraria en el sur de Santa Fe, Argentina". Ponencia presentada en el VII Congreso Latinoamericano de Sociología Rural. Quito, Ecuador. Noviembre 20 al 24, 2006.

Beillerot, Jacky, Blanchard-Laville, Claudine y Mosconi, Nicole (1998): 
Saber y relación con el saber. Buenos Aires, Argentina, Paidós.

Coriat, Benjamín (1982): El taller y el cronómetro. Ensayo sobre el taylorismo, el fordismo y la producción en masa. Madrid, Siglo XXI.

De Certeau, Michel (1996): La invención de lo cotidiano. I. Artes de hacer. México: Universidad Iberoamericana.

Durkheim, Émile (1976): “La educación: su naturaleza, su función”. En E. Durkheim, Educación como socialización (pp. 89-113). Salamanca, Sígueme.

Foucault, Michel (2008): La arqueología del saber. Buenos Aires, Argentina, Siglo XXI.

Gastaminza, Félix del Valle (2002): “El análisis documental de la fotografía". Cuadernos de documentación multimedia. $\mathrm{N}^{\circ} 2$. Junio de 1993. Ed. Rev. 2002.

Heras, Ana Inés (1995): “Living Bilingual, Interacting in Two Languages: An Ethnographic and Sociolinguistic Study of a Fourth Grade Bilingual Classroom". Tesis doctoral, Universidad de California en Santa Bárbara, California, U.S.A.

Heras, Ana Inés; Bergesio, Liliana y Burin, David (2004): “Trabajo etnográfico, sociolinguística interaccional y comunicación visual en la generación y análisis de datos en lenguajes diversos". Ponencia presentada en las IV Jornadas de Etnografía, CAS, IDES. Buenos Aires, Argentina. Agosto 25 al 27, 2004.

Heras, Ana Inés (2009a): "Pensando lo audiovisual en Ciencias sociales y humanidades. Método, técnica, teoría". Conferencia dictada en el Primer Congreso Nacional: Pensando lo audiovisual en Ciencias Sociales y Humanidades. Buenos Aires, Argentina. Abril 22 al 24, 2009.

Heras, Ana Inés (2009b): "Procesos de aprendizaje en proyectos de autonomía”. Revista IRICE. N²0, pp. 89-101.

Hernández, Valeria (2007): “El fenómeno económico de la soja y el empresario innovador". Desarrollo Económico. Revista de Ciencias Sociales. Volumen 47. N 187, 331-365.

Lahire, Bernard (2006): “Capítulo 7: Lógicas prácticas. El hacer y el decir sobre el hacer". En B. Lahire, El espíritu sociológico (pp. 137-155). Buenos Aires, Manantial. 
Marx, Carlos (1980): Capital y tecnología (Manuscritos inéditos 18611863). México, Terra Nova.

Marx, Carlos (1987): El Capital. Volúmenes I y III. México: Siglo XXI.

Miano, Amalia (2012): A este pueblo le vino la modernización de golpe. Reconfiguración de saberes y sentidos en torno a la tecnología en una Comuna del sur de la provincia de Santa Fe. Tesis de Doctorado no publicada, UBA.

Moll, Luis (1992): "Literacy Research in Community and Classrooms: A Sociocultural Approach". En R. Beach, J. L. Green, M. L. Kamil \& T. Shanahan (eds.), Multidisciplinary Perspectives on Literacy Research. (pp. 211-244). Illinois, NCTE.

Santa Barbara Classroom Discourse Group (1995): “Two languages, one community: An examination of educational opportunities". En R. Macías \& R. García Ramos, Changing schools for changing students, California, LMRI.

Sarlo, Beatriz (2004): La imaginación técnica. Sueños modernos de la cultura argentina. Buenos Aires, Nueva Visión.

Simone, Raffaele (2001): La tercera fase. Formas de saber que estamos perdiendo. Madrid: Santillana.

Spinosa, Martín (2005): Del "saber" al "saber ser". Las calificaciones en el nuevo escenario de las relaciones de trabajo. En A. Fernández (Comp.), Estado y relaciones laborales: transformaciones y perspectivas (pp. 145-167). Buenos Aires: Prometeo.

Torresan, Angela (2011): “Round Trip: Filming a Return Home”. Visual Anthropology Review, Vol. 27, pp. 119-130.

Vélez-Ibáñez, Carlos y Greenberg, James (1992): “Formation and Transformation of Funds of Knowledge Among US. Mexican Households". Anthropology and Education Quaterly 23(4), pp. 313-335.

Villafañe, Alicia (1998-1999): “Procesos globales y consecuencias locales. El caso de comunidades de la pampa bonaerense argentina". Etnia. Nro. 42-43, pp. 85-103. 